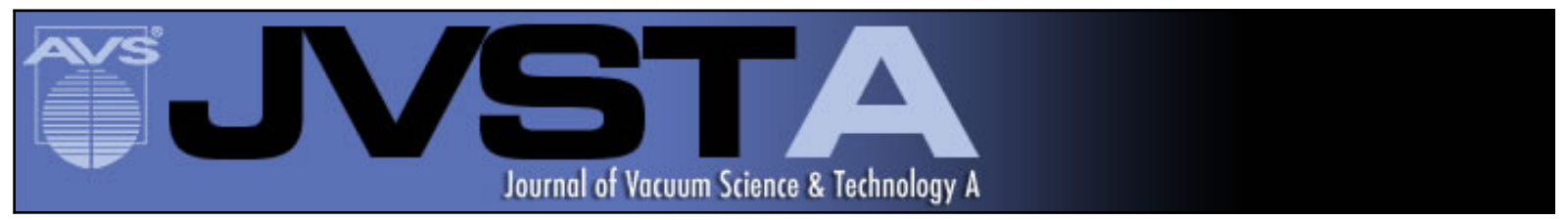

\title{
Transience of plasma surface modification as an adhesion promoter for polychlorotrifluorethylene
}

S. Subrahmanyan, J. G. Dillard, B. J. Love, M. Romand, and M. Charbonnier

Citation: Journal of Vacuum Science \& Technology A 20, 707 (2002); doi: 10.1116/1.1464837

View online: $\mathrm{http}: / / \mathrm{dx}$.doi.org/10.1116/1.1464837

View Table of Contents: http://scitation.aip.org/content/avs/journal/jvsta/20/3?ver=pdfcov

Published by the AVS: Science \& Technology of Materials, Interfaces, and Processing

\section{Articles you may be interested in}

Surface modification of silicon-containing fluorocarbon films prepared by plasma-enhanced chemical vapor deposition

J. Vac. Sci. Technol. A 23, 666 (2005); 10.1116/1.1943450

Development of an electrospray approach to deposit complex molecules on plasma modified surfaces

Rev. Sci. Instrum. 74, 4832 (2003); 10.1063/1.1618013

Contact angle measurements for adhesion energy evaluation of silver and copper films on parylene-n and SiO 2 substrates

J. Appl. Phys. 93, 919 (2003); 10.1063/1.1530362

Plasma surface modification for ion penetration barrier in organosiloxane polymer

J. Vac. Sci. Technol. B 20, 1884 (2002); 10.1116/1.1508803

Chemical interaction and adhesion characteristics at the interface of metals $(\mathrm{Cu}, \mathrm{Ta})$ and low-k cyclohexanebased plasma polymer (CHexPP) films

J. Vac. Sci. Technol. A 19, 1072 (2001); 10.1116/1.1340658
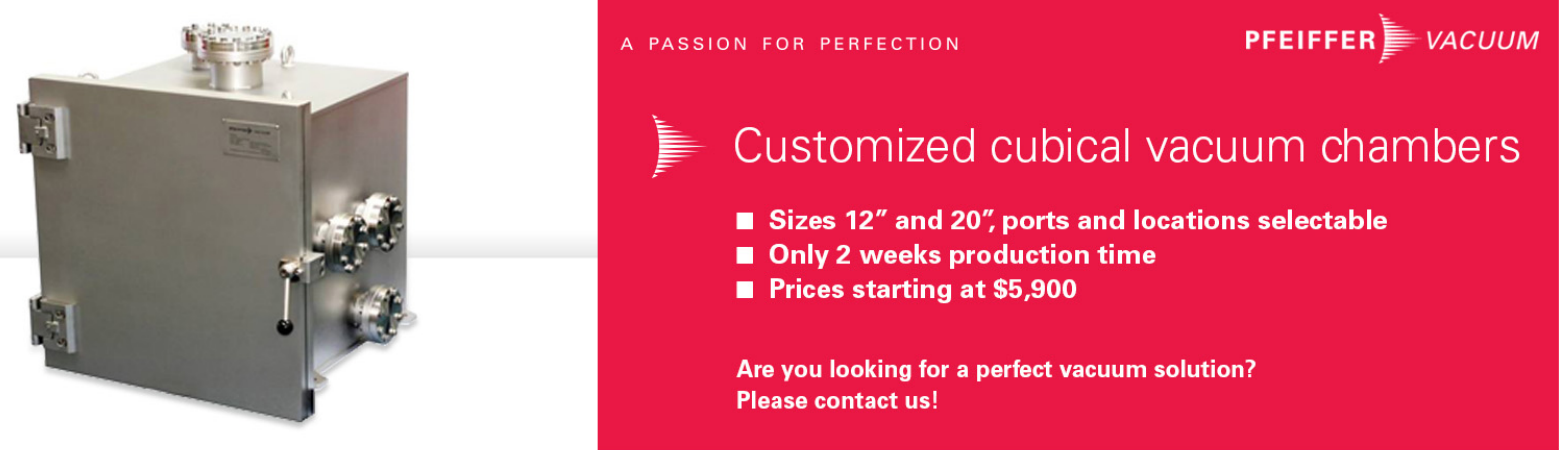
Copyright by the AIP Publishing. Subrahmanyan, S.; Dillard, J. G.; Love, B. J.; Romand, M.; Charbonnier, M., "Transience of plasma surface modification as an adhesion promoter for polychlorotrifluorethylene," J. Vac. Sci. Technol. A 20, 707 (2002); http://dx.doi.org/10.1116/1.1464837

\title{
Transience of plasma surface modification as an adhesion promoter for polychlorotrifluorethylene
}

\author{
S. Subrahmanyan \\ Departments of Materials Science and Engineering and Chemistry, Virginia Polytechnic Institute \\ and State University, Blacksburg, Virginia 24061 \\ J. G. Dillard ${ }^{\text {a) }}$ \\ Department of Chemistry, Virginia Polytechnic Institute and State University, Blacksburg, Virginia 24061 \\ B. J. Love ${ }^{\text {b) }}$ \\ Department of Materials Science and Engineering, Virginia Polytechnic Institute and State University, \\ Blacksburg, Virginia 24061
}

M. Romand and M. Charbonnier

Laboratorie de Sciences et Ingénierie des Surfaces, Université Claude Bernard-LYON1, 69622 Villeurbanne Cedex, France

(Received 21 May 2001; accepted 4 February 2002)

\begin{abstract}
Poly(chlorotrifluoroethylene) (PCTFE) and other fluoropolymers are increasingly used as inner layer dielectrics. However, these polymers have low surface energies and correspondingly poor adhesive properties. Results are presented on the use of a low-pressure ammonia plasma to enhance the surface bondability of PCTFE. The plasma modified PCTFE film surfaces were characterized by x-ray photoelectron spectroscopy and contact angle measurements. Surface modified films exhibited improved adhesion to electroless copper deposits $\left(180^{\circ}\right.$ peel test $)$ compared to coated PCTFE controls and that underwent no plasma exposure. Annealing studies were conducted between 30 and $100{ }^{\circ} \mathrm{C}$ to examine the stability of the plasma-modified surfaces. For samples annealed below $T_{g}$, contact angle measurements indicated that the plasma-introduced groups remained bound on the surface for four weeks. For specimens annealed above $T_{g}$, the surface functionalities were absorbed within the bulk and surface rearrangement occurred within $10 \mathrm{~h}$ of annealing time. As a result of rearrangement, the benefit of adhesion enhancement by plasma is lost and the adhesion to copper is reduced. () 2002 American Vacuum Society. [DOI: 10.1116/1.1464837]
\end{abstract}

\section{INTRODUCTION}

Poly(chlorotrifluoroethylene (PCTFE) is well known for its chemical and physical inertness, resistance to thermal aging, and low dielectric constant and loss. ${ }^{1}$ The resin's moisture barrier feature makes it highly desirable in the medical industry as a sealant. An alternative application, which is the topic of this research, is the use of PCTFE as a hot-melt adhesive in high frequency printed circuit manufacturing. Of particular interest is PCTFEs use as a microwave dielectric. ${ }^{2}$ A number of studies have examined surface modification methods with the overall goal of enhancing adhesion of dielectric layers to the substrate. Among the wet processes, defluorination by sodium naphthalenide has been most widely used in the industry. ${ }^{3-5}$ This method is an aggressive technique that often roughens and in severe cases pits the surface. McCarthy et al. have successfully used lithium reagents to chemically activate the surface by introducing planar functionalities. ${ }^{6-8}$

Dry processes generally employ reactive gases such as plasmas, ${ }^{9-11}$ coronas, ${ }^{12-14}$ and excimer lasers ${ }^{15,16}$ to introduce functionalities. All of these procedures are relatively inexpensive and have shown encouraging results. These pro-

\footnotetext{
a) Author to whom correspondence should be addressed; electronic mail: john.dillard@vt.edu

b) Author to whom correspondence should be addressed; electronic mail: blove@vt.edu
}

cesses are also preferred because they are fast, easy, effective, and in most cases, environmentally benign. Plasma treatment is employed not only for introducing surface functionalities, but also for surface cleaning, crosslinking and texturing. ${ }^{10}$ Charbonnier et al. have presented an in-depth study on the defluorinating potential of different gases. ${ }^{17,18}$ Ammonia plasma was most effective to defluorinate the polytetrafluoroethylene (PTFE) surface. Ma et al. have used an ammonia plasma to deflorinate the PTFE surface and graft copolymerize with aniline. ${ }^{19}$

For multilayer printed circuit wiring, bonding the fluoropolymer resin to a substrate base is critical. Melt processing softens the film sufficiently to conform to a featured substrate, but it causes the film to crystallize and embrittle upon cooling. ${ }^{20,21}$ Also, the modified groups diffuse into the bulk at melting temperatures. ${ }^{22}$ Therefore, an alternate adhesion enhancement procedure that avoids melt processing could be useful not only for multilayer construction but also for metallization. Since copper is the conductor of choice in most printed circuit constructions and has been deposited successfully on polyimides and PTFE, this study focuses on the adhesion of copper deposits on PCTFE and its copolymer surfaces. ${ }^{23,24}$ Ricco et al. have shown that electroless copper deposited on an etched PTFE surface yields excellent adhesion. ${ }^{24}$ The goals of the current study are to introduce and characterize functionality on PCTFE, to gauge the relative propensity for adhesive bonding, and to evaluate the 


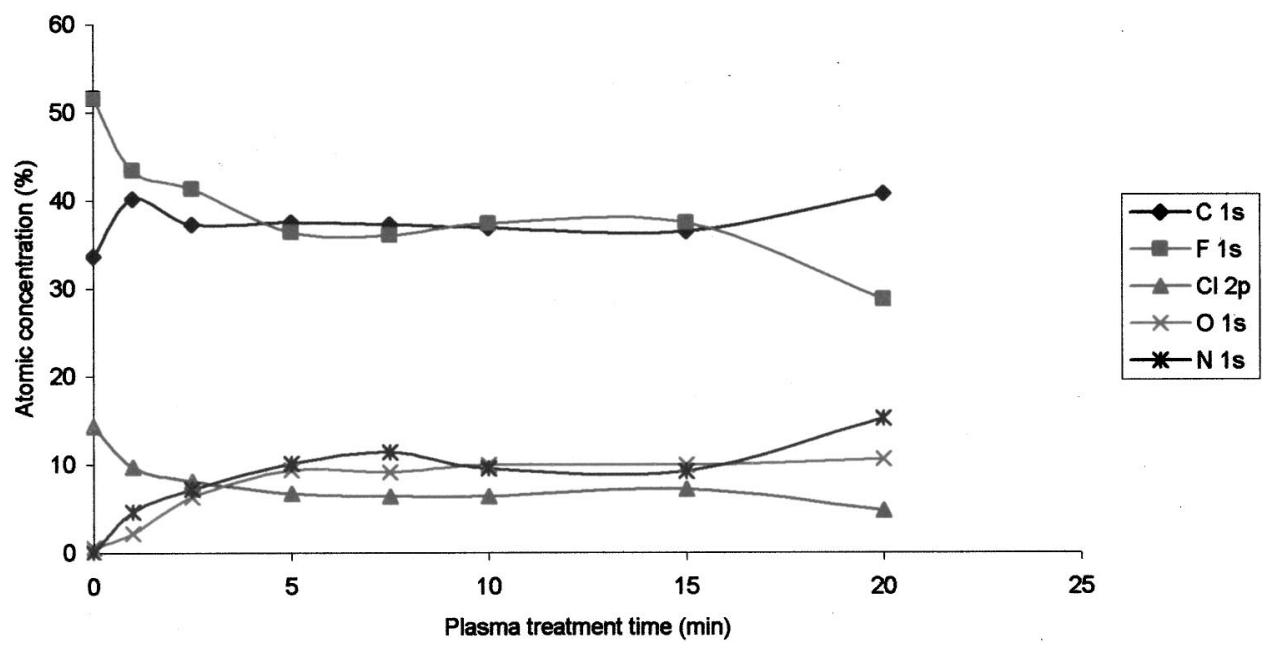

FIG. 1. XPS results showing defluorination, dechlorination, and introduction of oxygen and nitrogen.

stability of the plasma-introduced surface functionalities conditioned at elevated temperatures.

\section{EXPERIMENTAL DETAILS}

Polychlorotrifluoroethylene films, marketed under the trade name Aclar $^{\circledR}$, were obtained from Honeywell Inc. PCTFE copolymer film (with $\sim 4 \%$ polyvinylidene fluoride), $127 \mu \mathrm{m}$ thick, was used in all experiments. The $T_{g}$ of the film was $53{ }^{\circ} \mathrm{C}$ as determined by differential scanning calorimetry and $80^{\circ} \mathrm{C}$ from the $\tan \delta$ peak using dynamic mechanical analysis. All chemicals were ACS certified grade reagents, were purchased from Fisher Scientific, and were used "as received." The film samples, cut into $8 \mathrm{~cm} \times 2 \mathrm{~cm}$ coupons, were soaked in dichloromethane for $15 \mathrm{~min}$ and were wiped with Kimwipes ${ }^{\circledR}$ to degrease the specimens completely. Films were then dried in an oven in air at $50{ }^{\circ} \mathrm{C}$ for $24 \mathrm{~h}$.

Plasmas are mixtures of highly energetic radicals, ionized and metastable species produced by radio frequency (rf) radiation interacting with a feed gas. The chemical groups introduced on the surface result from the interaction of the reactive species with the substrate. Surface modification was carried out by room temperature, low-pressure rf plasma exposure in a March Instruments Plasmod ${ }^{\circledR}$ unit operating at 13.56 MHz and $50 \mathrm{~W}$. The plasma chamber was first evacuated to a pressure $<0.1$ Torr. The chamber was subsequently purged and filled with ammonia to a pressure of 0.2 Torr. The samples were exposed to the plasma for time periods varying from 1 to $20 \mathrm{~min}$. Purging of the reactor with the gas was continued for $30 \mathrm{~min}$ after the rf source was turned off. The samples were then removed and stored in a desiccator to minimize exposure to moisture.

The plasma-modified and virgin specimens were characterized by both x-ray photoelectron spectroscopy (XPS) and contact angle measurements. A Perkin-Elmer PHI 5400 model photoelectron spectrometer, equipped with a $\mathrm{Mg} K \alpha$ $\mathrm{x}$-ray source, was used to determine the surface chemical composition. Atomic concentrations were evaluated from $\mathrm{C}$ $1 s, \mathrm{~F} 1 s, \mathrm{Cl} 2 p, \mathrm{O} 1 s$, and $\mathrm{N} 1 s$ photopeaks recorded at a $45^{\circ}$ takeoff angle. The $\mathrm{C} 1 s$ photopeak was curve fit to cor- respond to $\mathrm{CF}_{2}, \mathrm{CFCl}, \mathrm{CFH}, \mathrm{CO}$, and $\mathrm{CN}$ components. $\mathrm{CF}_{2}$, $\mathrm{CFCl}$, and $\mathrm{CFH}$ component percentages were determined and the remaining $\mathrm{C} 1 s$ features were fit to account for $\mathrm{CO}$, $\mathrm{CN}$, and $\mathrm{CH} / \mathrm{CC}$ components. The concentrations of $\mathrm{F}, \mathrm{Cl}, \mathrm{O}$, and $\mathrm{N}$ containing carbon functionalities were determined from $\mathrm{C} 1 s$ curve fitting and were correlated with the individual $\mathrm{F}, \mathrm{Cl}, \mathrm{O}$, and $\mathrm{N}$ concentrations determined from $\mathrm{F} 1 s$, $\mathrm{Cl} 2 p, \mathrm{O} 1 s$, and $\mathrm{N} 1 s$ photopeaks.

Water contact angles were measured using a Ramé Hart 100 contact angle goniometer at room temperature and atmospheric pressure. An average of ten measured values was taken and the error is reported as standard deviation. Water and methylene iodide contact angles were measured at different times during annealing following equilibration at room temperature. Five droplets (each $5 \mu \mathrm{L}$ ) were observed for each condition and the average of ten contact angles was determined. Surface tension of the samples annealed at each temperature was determined at the end of the annealing period using the harmonic mean method for surface tension determination. ${ }^{25}$

Electroless copper deposition was carried out using a standard procedure on both the virgin copolymer and on specimens exposed to plasma for $20 \mathrm{~min} .{ }^{24}$ Prior to the copper deposition, the samples were rinsed with flowing deionized water. The deposition was done in three steps: (a)

TABLE I. Results of C $1 s$ photopeak curve fit giving percentages of different components.

\begin{tabular}{ccccccc}
\hline \hline & \multicolumn{5}{c}{$\mathrm{C} 1 s$ multiplex (\%)/binding energy (eV) } \\
\cline { 2 - 7 } $\begin{array}{c}\text { Plasma treatment } \\
\text { time (min) }\end{array}$ & $\mathrm{CF}_{2} /$ & $\mathrm{CFCl} /$ & $\mathrm{CFH} /$ & \multicolumn{1}{c}{$\mathrm{CO} /$} & $\mathrm{CN} /$ & $\mathrm{CH} / \mathrm{CC} /$ \\
\hline 0 & 291.0 & 289.8 & 288.0 & 287.0 & 286.0 & 285.0 \\
1.0 & 59.4 & 32.1 & 8.4 & $<0.2$ & $<0.1$ & $<0.1$ \\
2.5 & 43.4 & 16.1 & 10.9 & 9.0 & 13.8 & 6.7 \\
5.0 & 51.6 & 17.0 & 18.2 & 5.3 & 4.3 & 3.4 \\
7.5 & 39.2 & 17.1 & 24.2 & 7.3 & 5.5 & 4.7 \\
10.0 & 29.2 & 15.7 & 28.8 & 12.2 & 9.1 & 4.9 \\
15.0 & 38.1 & 22.1 & 20.6 & 8.4 & 6.4 & 4.5 \\
20.0 & 36.0 & 20.0 & 19.5 & 12.1 & 7.0 & 5.3 \\
\hline \hline
\end{tabular}


TABLE II. Comparison between concentrations of $\mathrm{F}, \mathrm{Cl}, \mathrm{O}$, and $\mathrm{N}$ calculated from $\mathrm{C} 1 s$ curve fit and recorded.

\begin{tabular}{|c|c|c|c|c|c|c|c|c|}
\hline \multirow{3}{*}{$\begin{array}{l}\text { Plasma } \\
\text { time } \\
\text { (min) }\end{array}$} & \multicolumn{8}{|c|}{ Atomic concentration $(\%)$} \\
\hline & \multicolumn{2}{|c|}{$\mathrm{F}$} & \multicolumn{2}{|c|}{$\mathrm{Cl}$} & \multicolumn{2}{|c|}{$\mathrm{O}$} & \multicolumn{2}{|c|}{$\mathrm{N}$} \\
\hline & Calculated & Recorded & Calculated & Recorded & Calculated & Recorded & Calculated & Recorded \\
\hline 0.0 & 54.0 & 51.5 & 10.8 & 14.3 & & & & \\
\hline 1.0 & 45.7 & 43.4 & 6.5 & 9.7 & 3.6 & 2.2 & 5.5 & 5.5 \\
\hline 2.5 & 45.3 & 41.3 & 6.3 & 8.1 & 2.0 & 6.3 & 1.6 & 7.2 \\
\hline 5.0 & 43.2 & 36.3 & 7.7 & 6.7 & 3.4 & 9.4 & 2.6 & 10.1 \\
\hline 7.5 & 37.9 & 36.2 & 5.8 & 6.3 & 4.5 & 9.3 & 3.4 & 11.3 \\
\hline 10.0 & 43.7 & 37.3 & 8.1 & 6.4 & 3.1 & 9.9 & 2.4 & 9.5 \\
\hline 15.0 & 40.6 & 37.3 & 7.3 & 7.2 & 4.4 & 9.9 & 2.6 & 9.2 \\
\hline 20.0 & 39.5 & 28.7 & 7.7 & 4.8 & 3.4 & 10.6 & 4.6 & 15.2 \\
\hline
\end{tabular}

sensitization: the specimens were immersed in a solution of $0.11 \mathrm{M} \mathrm{SnCl}_{2} / 0.48 \mathrm{M} \mathrm{HCl}$ with constant stirring for $30 \mathrm{~min}$ followed by rinsing in flowing de-ionized water. (b) Activation: the samples were immersed in $1.4 \mathrm{mM} \mathrm{PdCl} / 30 \mathrm{mM}$ $\mathrm{HCl}$ solution for $30 \mathrm{~min}$ with continuous stirring, and (c) deposition: the films were exposed to a solution of $14 \mathrm{mM}$ $\mathrm{CuSO}_{4}, 89 \mathrm{mM} \mathrm{KNaC}_{4} \mathrm{H}_{4} \mathrm{O}_{6}, 100 \mathrm{mM} \mathrm{NaOH}$, and $0.12 \mathrm{M}$ aqueous $\mathrm{HCHO}$ to deposit copper. The formaldehyde solution was added in three equivalent portions, the total amounting to $0.12 \mathrm{M}$ in solution, to control the reaction rate and minimize side reactions. The extent of the reaction could be observed in the form of both copper deposits on the polymer film and hydrogen evolution from the solution. Formaldehyde from previous additions was fully consumed (no more bubbles) before the next portion was added. During the sensitization step, $\mathrm{Sn}^{2+}$ is adsorbed on the surface. Subsequently when the polymer is immersed in the $\mathrm{PdCl}_{2}$ solution, $\mathrm{Pd}^{2+}$ is adsorbed. Palladium sites act as nucleation sites for deposition of copper from $\mathrm{Cu}^{2+}$ solution and $\mathrm{HCHO}$ serves as a reducing agent. The reduction of copper occurs as follows:

$$
\mathrm{Cu}^{2+}+2 \mathrm{HCHO}+4 \mathrm{OH}^{-} \rightarrow \mathrm{Cu}+2 \mathrm{HCOO}^{-}+2 \mathrm{H}_{2} \mathrm{O}+\mathrm{H}_{2} \text {. }
$$

An alternative deposition route was studied whereby the sensitization and activation steps were eliminated and a gold layer was deposited on PCTFE to act as nucleation sites for copper electroless plating. Using an Edwards ${ }^{\circledR}$ S150B sputtering system, gold was directly deposited for $10 \mathrm{~s}$ on the plasma treated and the control specimens. Copper was then deposited electrolessly from solution as described earlier.

The areal uniformity of the copper deposit was examined using an Olympus ${ }^{\circledR}$ BH2 optical microscope under $250 \times$ magnification and photographed using an Olympus ${ }^{\circledR}$ DP10 camera.

Peel tests on copper deposited film samples were performed according to the test standard American Society for Testing and Materials (ASTM) D3359 method A. ${ }^{26}$ A metallized area free from blotches or imperfections was selected. Two straight line cuts of $\sim 4 \mathrm{~cm}$ were made in the form of an " $\mathrm{X}$ " with a sharp scalpel so that the smaller angle was between $30^{\circ}$ and $45^{\circ}$. Scotch Magic ${ }^{\mathrm{TM}}$ tape about $8 \mathrm{~cm}$ long was placed on the incisions and rubbed firmly with the eraser end of a pencil. After about $90 \mathrm{~s}$ the tape was pulled in one continuous smooth motion at an angle close to $180^{\circ}$. As described in ASTM D3359 A, the results were ranked on a scale $0-5$, where 0 represented complete removal of copper and 5 indicated excellent adhesion and no removal. The peel areas were then re-examined optically to evaluate the extent of deposit removal.

Annealing studies were performed on the modified films to gauge the stability of the functionalities below and above $T_{g}$. The samples exposed to the plasma for $20 \mathrm{~min}$ were annealed in air at four different temperatures 30, 50, 80, and $100{ }^{\circ} \mathrm{C}$. Electroless copper deposition via the $\mathrm{SnCl}_{2} / \mathrm{PdCl}_{2}$

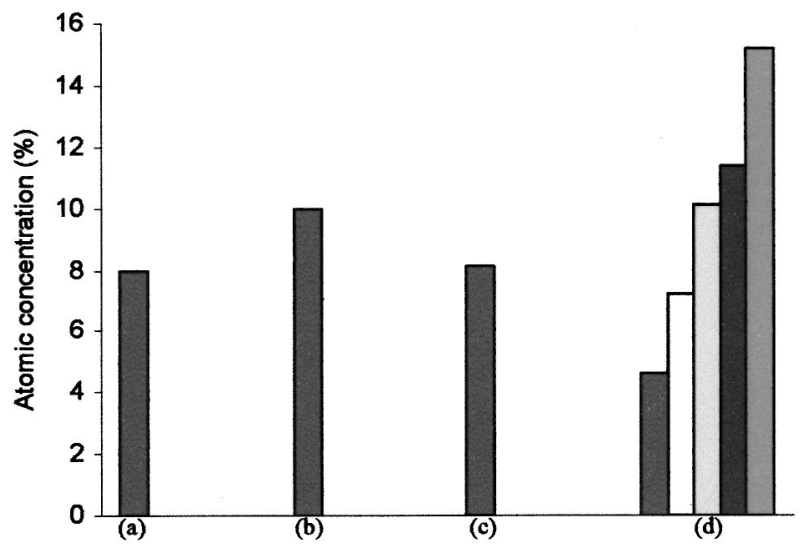

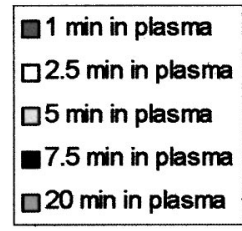

FIG. 2. Nitrogen percentage due to ammonia plasma treatment, (a) on PP after 1 min (see Ref. 21), (b) on PC after $1 \mathrm{~min}$ (see Ref. 26), (c) on PTFE after 1 min (see Ref. 16), and (d) on PCTFE for different time periods (this work). 


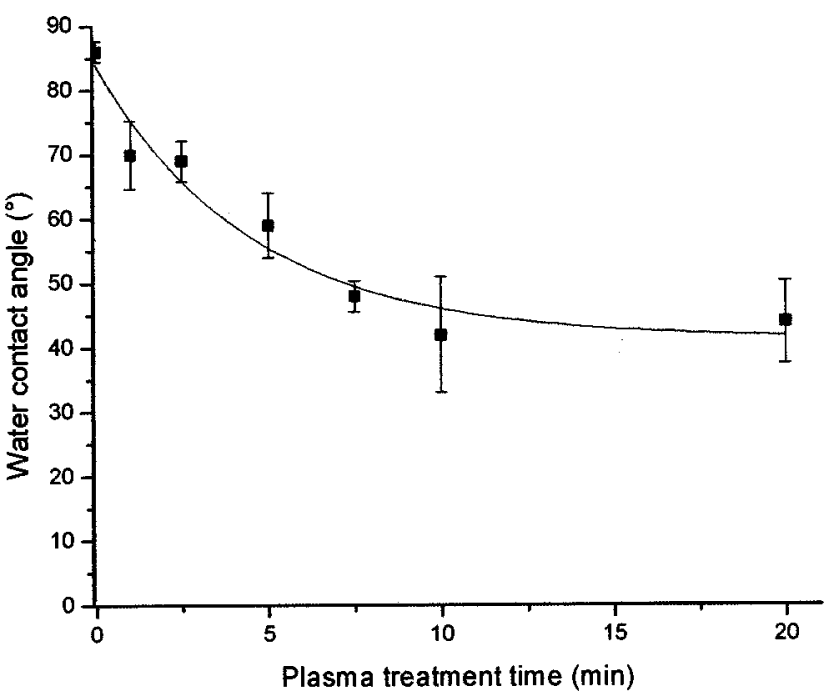

FIG. 3. Water contact angle as a function of ammonia plasma treatment time and a corresponding time dependent exponential fit of the contact angle.

route and adhesion testing was carried out on the films after annealing for 4 weeks at all four temperatures.

\section{RESULTS AND DISCUSSION}

Atomic concentrations from XPS measurements are shown as a function of ammonia plasma treatment in Fig. 1. The principal elements detected are carbon, fluorine, chlorine, oxygen, and nitrogen. Dramatic decreases in $\mathrm{F}$ and $\mathrm{Cl}$ concentrations are observed within 1 min of exposure compared to no plasma treatment. The drop in $\mathrm{F}$ and $\mathrm{Cl}$ concentrations is accompanied by an increase in $\mathrm{O}$ and $\mathrm{N}$ concentrations (not present in the virgin polymer). With longer plasma exposure, more modification occurs on the surface and consequently $\mathrm{C}, \mathrm{O}$, and $\mathrm{N}$ incorporations increase. The precision in the reported XPS percent values is $10 \%$. Table I shows results from the $\mathrm{C} 1 s$ peak curve fits. The oxygen peak can be resolved into two components corresponding to $\mathrm{C}=\mathrm{O}$ at $532.0 \mathrm{eV}$ and $\mathrm{C}-\mathrm{O}$ at $533.5 \mathrm{eV}$. The intensity ratios of the two components remain nearly constant at $4: 1$. The multiplex spectrum for $\mathrm{N}$ shows a single peak at around
TABLE III. Scotch ${ }^{\mathrm{TM}}$ tape peel test results on the four different samples.

\begin{tabular}{lcc}
\hline \hline Material & $\begin{array}{c}\text { Postplasma } \\
\text { processing } \\
\text { conditions }\end{array}$ & \multicolumn{1}{c}{ Ranking } \\
\hline Copolymer control & $\mathrm{SnCl}_{2} / \mathrm{PdCl}_{2} / \mathrm{Cu}$ & $\begin{array}{c}\text { 0: Complete } \\
\text { removal beyond the } \\
\text { incisions }\end{array}$ \\
$\begin{array}{l}\text { Copolymer } \\
\text { processed in } \mathrm{NH}_{3} \\
\text { plasma for } 20 \mathrm{~min}\end{array}$ & $\mathrm{SnCl}_{2} / \mathrm{PdCl}_{2} / \mathrm{Cu}$ & $\begin{array}{c}\text { 4: Slight removal } \\
\text { along the incisions }\end{array}$ \\
$\begin{array}{l}\text { Copolymer control } \\
\text { Copolymer } \\
\text { processed in } \mathrm{NH}_{3} \\
\text { plasma for } 20 \mathrm{~min}\end{array}$ & $\mathrm{Au} / \mathrm{Cu}$ & $\begin{array}{c}\text { 0: Complete } \\
\text { removal beyond the } \\
\text { incisions }\end{array}$ \\
& $\mathrm{Au} / \mathrm{Cu}$ & $\begin{array}{c}\text { 0: Complete } \\
\text { removal beyond the } \\
\text { incisions }\end{array}$ \\
\hline \hline
\end{tabular}

$400.0 \mathrm{eV}$. The oxygen peak curve fit and nitrogen peak analysis show the presence of two different types of oxygens and one kind of $\mathrm{N}$, namely, $\mathrm{C}=\mathrm{O}, \mathrm{C}-\mathrm{O}$, and $\mathrm{C}-\mathrm{N}$. C $1 s$ spectra show that the decrease in $\mathrm{F}$ and $\mathrm{Cl}$ concentrations are concordant with a reduction in $\mathrm{CF}_{2}$ (at $291.0 \mathrm{eV}$ ) and $\mathrm{CFCl}$ (at $298.8 \mathrm{eV}$ ) components. Since $\mathrm{Cl}$ is more labile and susceptible to removal than $\mathrm{F}$, loss of $\mathrm{Cl}$ occurs more readily. ${ }^{8}$ Loss of chlorine functionality results in the formation of $\mathrm{CFH} / \mathrm{CFCH}_{3}$ groups and the appearance of the component corresponding to this grouping is noted at $288.0 \mathrm{eV}$. Curve fitting of the C $1 s$ peak was very complex and instead of incorporating too many components into the fit, the contributions due to carbon in $\mathrm{C}=\mathrm{O}$ and $\mathrm{C}-\mathrm{O}$ were combined together at $287.0 \mathrm{eV}$. Decreases in $\mathrm{F}$ and $\mathrm{Cl}$ concentrations with corresponding decreases in $\mathrm{C}-\mathrm{F}$ and $\mathrm{C}-\mathrm{Cl}$ components are indicative of surface defluorination and dechlorination. Since the compositional analyses shown are the result from a single XPS run for each time period, more importance is given to the overall trend, which indicates increasing concentration of polar groupings that contain $\mathrm{O}$ and $\mathrm{N}$ with increasing plasma treatment time. Calculations of $\mathrm{F}, \mathrm{Cl}, \mathrm{O}$, and $\mathrm{N}$ concentrations were performed from the curve fit $\mathrm{C} 1 s$ peak. The calculated $\mathrm{F}$ and $\mathrm{Cl}$ concentrations are in good agreement with the recorded concentrations from the individual $\mathrm{F}$

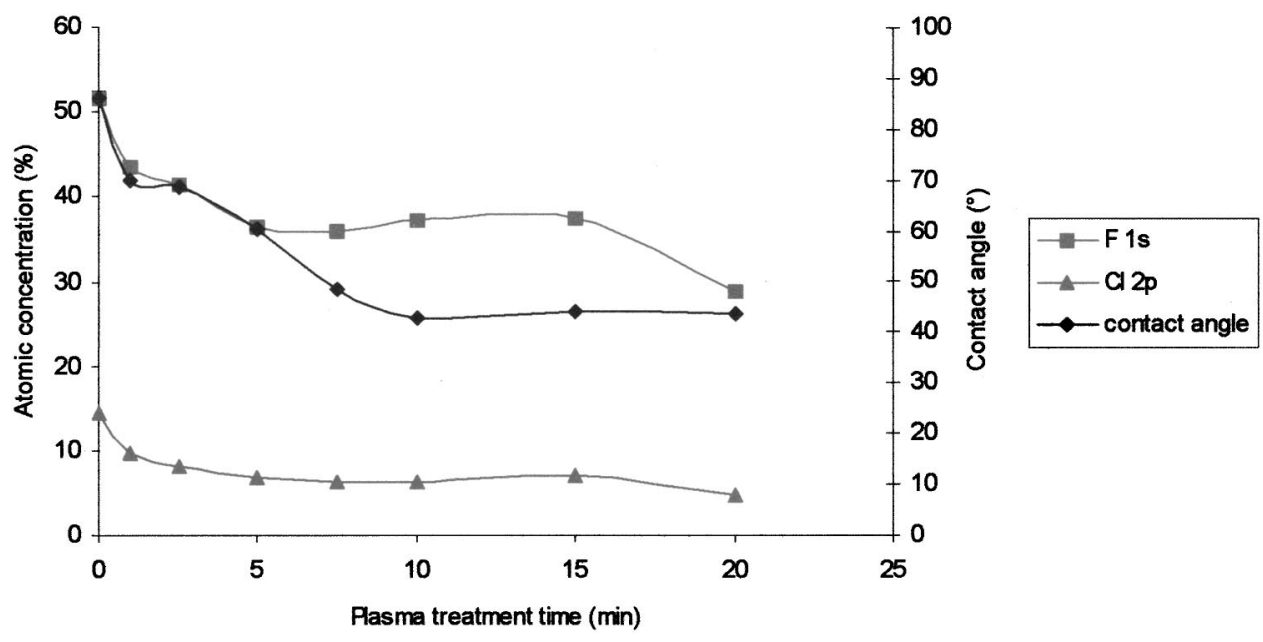

FIG. 4. Comparison of $\mathrm{F}$ and $\mathrm{Cl}$ concentrations with contact angle. 


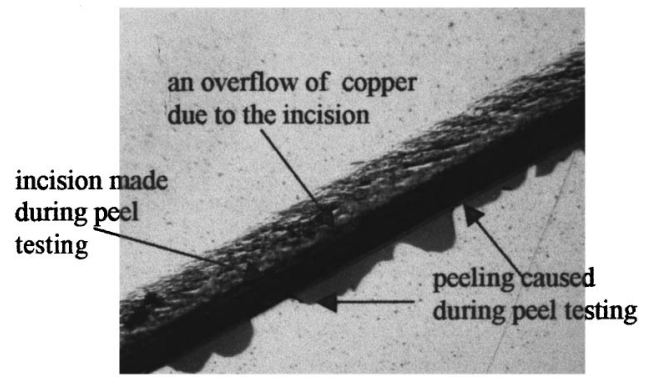

FIG. 5. Top view of a specimen revealing minimal peeling of copper in the peel test.

and $\mathrm{Cl}$ peaks as shown in Table II. The error involved is $<5 \%$. The concentrations of $\mathrm{O}$ and $\mathrm{N}$ components in the $\mathrm{C}$ $1 s$ peak are in agreement with the observed concentrations of $\mathrm{O}$ and $\mathrm{N}$ with $<2 \%$ error for untreated and 1 min treatment time in the plasma. However, with higher plasma treatment times, the $\mathrm{C} 1 s$ curve fit is more complex. The error involved is $>5 \%$ in every case. This is due to added uncertainty in calculating the percentages for the components in the $\mathrm{C} 1 s$ curve fit; only one $\mathrm{O}$ or $\mathrm{N}$ is assumed bound with each carbon. However, it is possible that two or more $\mathrm{O}$ and $\mathrm{N}$ atoms are bonded to each carbon in the form of carboxyl, amide, or amine functionalities. The exact nature of $\mathrm{O}$ and $\mathrm{N}$

(a)
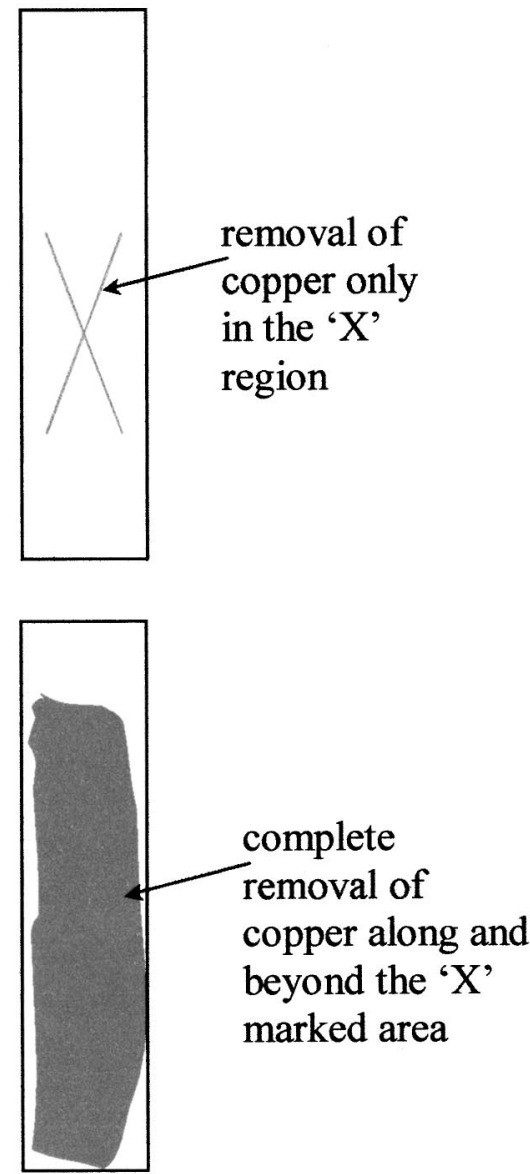

(b)

FIG. 6. Schematic of ranking; copper observed on the tape side; (a) rank 4 and (b) rank 0. functional groups was not established unequivocally by XPS. Failure to fit the $\mathrm{C} 1 \mathrm{~s}$ photopeaks exactly explains the higher concentrations of $\mathrm{O}$ and $\mathrm{N}$ in the recorded data (Table II).

Figure 2 compares the surface nitrogen composition from other ammonia plasma investigations with the current work. Polypropylene (PP), ${ }^{23}$ polycarbonate (PC), ${ }^{27}$ and PTFE, ${ }^{17}$ each treated for $1 \mathrm{~min}$ in an ammonia plasma, showed approximately $8 \%, 10 \%$, and $8 \%$ increase in nitrogen content, respectively, compared to the corresponding control sample. Similarly, PCTFE also showed an increase in nitrogen content within 1 min of plasma treatment. However, greater incorporation of $\mathrm{N}$ is observed in PP, PC, and PTFE. The higher content of $\mathrm{N}$ in PP, PC, and PTFE is attributed to different experimental setups and conditions. Different plasma treatment times were not studied for the PP, PC, or PTFE substrates by the authors. The results from the current work show that increasing plasma treatment time increases nitrogen incorporation.

The contact angle results correlated with the XPS data. Clearly, with surface defluorination the surface becomes more hydrophilic as evidenced by smaller water contact angles (Fig. 3). A $42^{\circ}$ change was observed in the contact angle with plasma exposure time and the dynamic response in contact angle followed an exponential curve with a time constant of $4.7 \mathrm{~min}\left(r^{2}=0.95\right)$. The error in the measured contact angles was less than $5^{\circ}$ in all cases except for the 10 min plasma treated sample (in which case the error was $9^{\circ}$ ). A separate correlation between the decrease in $\mathrm{F}$ and $\mathrm{Cl}$ concentrations by XPS and the drop in contact angle is apparent from Fig. 4.

To investigate whether the plasma treatment is a viable adhesion promotion method, deposition of copper followed by peel testing and fractographic analysis of the peel surfaces were performed. Scotch ${ }^{\mathrm{TM}}$ tape pulloff tests were performed on four different samples as described in Table III. The results of the pulloff tests are given in Table III. While the plasma processed sample that had undergone sensitization with $\mathrm{SnCl}_{2} / \mathrm{PdCl}_{2}$ showed minimal or trace peeling along the incisions, the control (no plasma treatment) with the same predeposition steps showed complete removal of deposited copper beyond the $\mathrm{X}$ area. Hence, the former case was ranked 4 and the latter 0 based on the ASTM test standard. ${ }^{26}$ Figure 5 shows a photograph of the top view of a section of the sample that was peeled after ammonia plasma treatment for $20 \mathrm{~min}$ and subsequent copper deposition via the $\mathrm{SnCl}_{2} / \mathrm{PdCl}_{2}$ route. The incision brings about an overflow of copper that is piled on one side (top side). The sparse removal of copper due to peeling of the tape is evidenced on the other side. The representations in Figs. 6(a) and 6(b) reveal the extent of copper removal by examining the tape side of a debonded specimen. Figure 6(a) shows sparse removal of copper only along the $\mathrm{X}$ shaped incision. Figure 6(b) shows complete removal of copper along and beyond the $\mathrm{X}$ marked area.

Since copper deposition requires the presence of specific nucleation sites in the form of a noble metal to initiate deposition, an alternate route was investigated using direct vapor deposition of $\mathrm{Au}$ on the polymer. Peel tests on plasma 


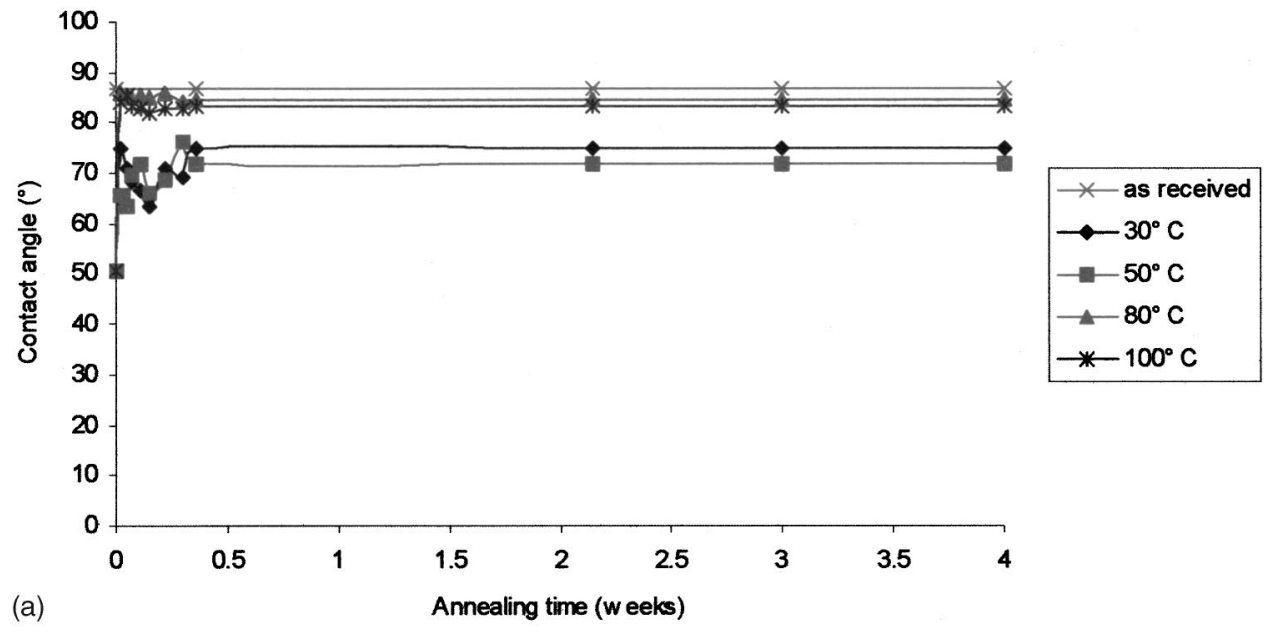

FIG. 7. (a) Water contact angle results for different annealing times and temperatures. (b) Magnified plot of the re-

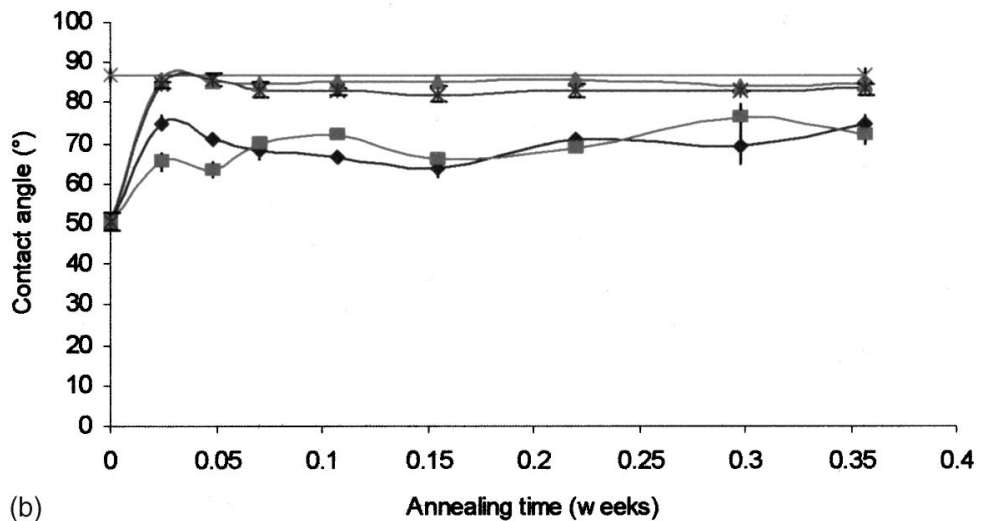
gion between 0 and $60 \mathrm{~h}$ ( 0.36 weeks).

treated, vapor deposited and control specimens exhibited total removal of copper beyond the scratches.

The $\mathrm{SnCl}_{2}$ and $\mathrm{PdCl}_{2}$ treatment steps are crucial to anchor copper deposits to the polymer film. Anchoring sites on the film are provided by $\mathrm{Sn}^{2+}$, which tends to complex with the organic groupings introduced by the plasma; subsequently $\mathrm{Pd}^{2+}$ reacts with $\mathrm{Sn}^{2+}$ to form $\mathrm{Pd}$ which is an active site for copper deposition. ${ }^{24}$ Charbonnier et al. ${ }^{27-29}$ argue that $\mathrm{Sn}^{2+}$ selectively adsorbs only to the oxygenated species on the polymer surface while $\mathrm{Pd}^{2+}$ adsorbs only to the nitrogenated species. Since both oxygen and nitrogen functionalities are introduced on plasma-treated PCTFE, both $\mathrm{Sn}^{2+}$ and $\mathrm{Pd}^{2+}$ should bind to the modified polymer surface but to different groupings.

Mechanistic studies have indicated that $\mathrm{Sn}^{2+}$ is involved in the reduction of $\mathrm{Pd}^{2+} \cdot{ }^{24}$ However, other studies have shown that $\mathrm{HCHO}$ from step (c) drives the reduction of $\mathrm{Pd}^{2+}$ and $\mathrm{Sn}^{2+}$ aids the reaction by reducing the activation energy. ${ }^{27}$ The formation of metallic palladium is necessary to initiate copper deposition. $^{27}$ The net consequence is improved adhesion as a result of plasma treatment, sensitization, and activation. In the absence of a similar anchor, copper films electrolessly deposited on substrates coated with very thin Au films peel off easily with Au on the tape side of the peel debond. The Au atoms are weakly bound on the surface and can be easily detached by scraping.

Annealing of plasma-exposed samples was performed to judge the stability of the plasma-induced functionalities. The samples were characterized by contact angle measurements after annealing. Contact angles were measured at short time intervals for 2 weeks. Thereafter, measurements were taken at the end of the third and fourth weeks. The results are shown in Figs. 7(a) and 7(b). Figure 7(a) shows the plots of contact angle versus annealing time for the entire period of observation. Figure 7(b) shows an expanded view of the initial period where most of the changes occur. For experiments at 80 and $100^{\circ} \mathrm{C}$, temperatures above $T_{g}$, the contact angles level off fairly quickly (within $5 \mathrm{~h}$ of annealing) and approach the limiting value (that for the control). For tempera-

TABLE IV. Results of XPS run on samples after annealing for 4 weeks.

\begin{tabular}{|c|c|c|c|c|c|}
\hline \multirow[t]{2}{*}{ Sample } & \multicolumn{5}{|c|}{ Atomic concentration (\%) } \\
\hline & $\mathrm{C}$ & $\mathrm{F}$ & $\mathrm{Cl}$ & $\mathrm{O}$ & $\mathrm{N}$ \\
\hline Virgin polymer & 33.6 & 51.5 & 14.3 & 0.6 & $<0.1$ \\
\hline $\begin{array}{l}\text { Ammonia plasma treated for } \\
20 \text { min and not annealed }\end{array}$ & 40.7 & 28.7 & 4.8 & 10.6 & 15.2 \\
\hline $\begin{array}{l}\text { Ammonia plasma treated for } \\
20 \text { min and not annealed at } 30^{\circ} \mathrm{C}\end{array}$ & 44.8 & 37.0 & 6.5 & 10.6 & 1.1 \\
\hline $\begin{array}{l}\text { Ammonia plasma treated for } \\
20 \text { min and not annealed at } 50{ }^{\circ} \mathrm{C}\end{array}$ & 41.3 & 37.3 & 5.9 & 9.1 & 6.4 \\
\hline $\begin{array}{l}\text { Ammonia plasma treated for } \\
20 \text { min and not annealed at } 80{ }^{\circ} \mathrm{C}\end{array}$ & 35.1 & 51.0 & 10.3 & 2.4 & 1.1 \\
\hline $\begin{array}{l}\text { Ammonia plasma treated for } \\
20 \text { min and not annealed at } 100{ }^{\circ} \mathrm{C}\end{array}$ & 37.8 & 47.7 & 7.9 & 5.1 & 1.4 \\
\hline
\end{tabular}


TABLE V. Surface energies of samples annealed for 4 weeks at different temperatures as calculated by the two solvent method.

\begin{tabular}{lc}
\hline \hline Temperature & Surface tension $(\mathrm{mN} / \mathrm{m})$ \\
\hline Untreated & 34.0 \\
$30^{\circ} \mathrm{C}$ & 38.5 \\
$50^{\circ} \mathrm{C}$ & 39.5 \\
$80^{\circ} \mathrm{C}$ & 33.5 \\
$100^{\circ} \mathrm{C}$ & 34.2 \\
\hline \hline
\end{tabular}

tures lower than $T_{g}$, the rate of change in contact angle to its limiting value is much slower. By the end of 4 days, all samples had approached a limiting value. A constancy in the contact angle values is observed until the end of 4 weeks. A similar trend was also observed for methylene iodide contact angles on annealed samples. XPS results obtained at the end of 4 weeks, shown in Table IV, revealed smaller amounts of oxygen and nitrogen functionalities on the samples annealed at 80 and $100{ }^{\circ} \mathrm{C}$. Also, the $\mathrm{F}$ and $\mathrm{Cl}$ concentrations were close to those of virgin polymer. For the specimens annealed at 30 and $50{ }^{\circ} \mathrm{C}$, some of the plasma-introduced groupings containing $\mathrm{CO}$ and $\mathrm{CN}$ were retained even at the end of 4 weeks.

Surface tension results for the samples annealed for 4 weeks are given in Table V. Highest surface tension values were noted for samples annealed at 30 and $50{ }^{\circ} \mathrm{C}$. This corroborates with XPS results, which revealed significant concentrations of $\mathrm{O}$ and $\mathrm{N}$ at the end of annealing period (Table IV). The surface tension values for the samples annealed at 80 and $100^{\circ} \mathrm{C}$ were comparable to the untreated sample indicating near complete rearrangement of the surface. Again, this result is concordant with the XPS results, which indicate residual of $\mathrm{O}$ or $\mathrm{N}$ after annealing at these temperatures.

Peel tests conducted on these samples at the end of 4 weeks, showed that the adhesive strength was not preserved. All samples showed complete peeling of the deposited copper and, hence, a ranking of 0 (zero). This is probably because the small island groups with $\mathrm{O}$ and $\mathrm{N}$ remaining on the surface are not sufficient to provide good adhesion. Bee and McCarthy have studied the behavior of carboxylic acid and oxazonline functionality on PCTFE with annealing. ${ }^{6}$ A similar response in the measured contact angle was observed. XPS spectra taken at different takeoff angles showed migration of the functionalities into the bulk and reorganization of the surface. ${ }^{6}$ At temperatures above $T_{g}$, PCTFE exhibits increased chain mobility that hastens surface rearrangement. Below $T_{g}$, long-range motions are retarded which helps to maintain plasma-induced functionalities on the surface.

\section{CONCLUSIONS}

The following conclusions can be drawn from the earlier discussion above.

Ammonia plasmas effectively introduce organic polar functionality containing $\mathrm{CO}$ and $\mathrm{CN}$ groupings on PCTFE film surfaces as evidenced by XPS measurements. The plasma induced moieties make the surface more hydrophilic based on contact angle data.
The higher surface energy of the functionalized surface creates a driving force for surface reorganization based on the minimization of surface energy. The transience of the plasma-introduced groups was confirmed by the annealing studies above $T_{g}$. The hydrophilic groups introduced on the surface are absorbed into the bulk during annealing. Thus, the plasma modifications that enhance wetting are unsuitable for high temperature lamination.

The peel test results show that the adhesion of electrolessly deposited copper to plasma exposed polymer films is superior compared to attachment to other cleaned polymer films. The treatment steps involving $\mathrm{SnCl}_{2} / \mathrm{PdCl}_{2}$ preceding copper deposition appear necessary to bond copper to the polymer.

${ }^{1}$ T. S. Laverghetta, Proc. 44th Electronic Components and Technology Conference, 1994, p. 539.

${ }^{2}$ D. N. Light and J. R. Wilcox, Proc. 44th Electronic Components and Technology Conference, 1994, p. 542.

${ }^{3}$ J. T. Marchesi, K. Ha, A. Garton, G. S. Swei, and K. W. Kristal, J. Adhes. 36, 55 (1991).

${ }^{4}$ J. T. Marchesi, H. T. Keith, and A. Garton, J. Adhes. 39, 185 (1992).

${ }^{5}$ R. R. Rye, A. J. Howard, and A. J. Ricco, Thin Solid Films 262, 73 (1995).

${ }^{6}$ T. G. Bee and T. J. McCarthy, Macromolecules 25, 2093 (1992).

${ }^{7}$ M. S. Shoichet and T. J. McCarthy, Macromolecules 24, 982 (1991).

${ }^{8}$ A. J. Dias and T. J. McCarthy, Macromolecules 20, 2068 (1987).

${ }^{9}$ F. D. Egitto and L. J. Matienzo, IBM J. Res. Dev. 38, 423 (1994).

${ }^{10}$ E. M. Liston, L. Martinu, and M. R. Wertheimer, J. Adhes. Sci. Technol. 7, 1091 (1993).

${ }^{11}$ L. J. Matienzo, J. A. Zimmerman, and F. D. Egitto, J. Vac. Sci. Technol. A 12, 2662 (1994).

${ }^{12}$ F. Garbassi, M. Morra, and E. Occhiello, Polymer Surfaces: From Physics to Technology (Wiley, Chichester, 1994), p. 225.

${ }^{13}$ H. Iwata, A. Kishida, M. Suzuki, Y. Hata, and Y. Ikada, J. Polym. Sci., Polym. Chem. Ed. 26, 3309 (1988).

${ }^{14}$ M. Strobel, C. Dunatov, J. M. Strobel, C. S. Lyons, S. J. Perron, and M. C. Morgen, J. Adhes. Sci. Technol. 3, 321 (1989).

${ }^{15}$ K. Revesz, B. Hopp, and Z. Bor, Langmuir 13, 5593 (1997).

${ }^{16}$ K. Revesz, B. Hopp, and Z. Bor, Appl. Surf. Sci. 109, 222 (1997).

${ }^{17}$ M. Charbonnier, M. Romand, M. Alami, and T. M. Duc, in Polymer Surface Modification: Relevance to Adhesion, edited by K. L. Mittal (VSP, Utrecht, 2000), Vol. 2, pp. 3-27.

${ }^{18}$ M. Charbonnier, M. Romand, and M. Alami, in Polymer Surface Modification: Relevance to Adhesion, edited by K. L. Mittal (VSP, Utrecht, 2000), Vol. 2, pp. 29-43.

${ }^{19}$ Z. H. Ma, K. L. Tan, A. D. Alian, E. T. Kang, and K. G. Neoh, J. Vac. Sci. Technol. A 19, 2471 (2001).

${ }^{20}$ J. L. Longhenry, B. J. Love, and N. S. Murthy, J. Mater. Sci. 32, 2283 (1997).

${ }^{21}$ B. J. Love, K. Cherry, J. L. Longhenry, N. S. Murthy, and C. Bednarczyk, J. Mater. Sci. Lett. 17, 1681 (1998).

${ }^{22}$ T. G. Bee, E. M. Cross, A. J. Dias, K. W. Lee, M. S. Shoichet, and T. J. McCarthy, J. Adhes. Sci. Technol. 6, 719 (1992).

${ }^{23}$ M. Charbonnier, M. Romand, G. Stremsdoerfer, and A. Fares-Karam, Recent Res. Dev. Macromol. Res. 4, 27 (1999).

${ }^{24}$ R. R. Rye and A. J. Ricco, J. Electrochem. Soc. 140, 1763 (1993).

${ }^{25} \mathrm{~S}$. Wu, Polymer Interface and Adhesion (Marcel Dekker, New York, 1982), p. 178

${ }^{26}$ ASTM D 3359-97, Standard Test Methods for Measuring Adhesion by Tape Test, Test Method A.

${ }^{27}$ M. Charbonnier, M. Romand, E. Harry, and M. Alami, J. Appl. Electrochem. 31, 57 (2001).

${ }^{28}$ M. Charbonnier, M. Alami, and M. Romand, J. Electrochem. Soc. 143, 472 (1996)

${ }^{29}$ M. Charbonnier, M. Alami, and M. Romand, J. Appl. Electrochem. 28, 449 (1998). 